This is the peer reviewed version of the following article:

"Digital Humanities and the Study and Teaching of North American Religions." Religion Compass, vol. 10, no. 2, 2016, pp. 307-316.

which has been published in final form at https://doi.org/10.1111/rec3.12226. This article may be used for non-commercial purposes in accordance with Wiley Terms and Conditions for Use of Self-Archived Versions.

\title{
Digital Humanities and the Study and Teaching of North American Religions
}

Abstract: The digital humanities are a collection of methodologies with a long history in the disciplines of literature, linguistics, media studies, and pedagogy. These methodologies and the scholars who employ them have recently gained widespread attention among academics and observers of higher education. While the digital humanities have deep roots in the field of religious studies, most scholars of religion have been relatively slow to embrace digital methods for research and pedagogy. This essay provides an introduction to the cluster of research and teaching methods generally grouped under the term "digital humanities." Digital humanists create digital archives, research collections, and exhibits; map and visualize information using online tools; and develop and apply computational methods of textual and visual analysis. This essay offers examples of scholarship and pedagogy on North American religions that use each of these methodologies, and concludes with a brief discussion of resources for learning about and becoming involved with digital humanities work.

\section{Introduction: What are the Digital Humanities?}

The digital humanities integrate computer applications with humanities research, pedagogy, and dissemination. It is most helpful to think of the digital humanities, not as a field or a discipline, but as a set of loosely related methodologies and projects that stretch 
across fields and disciplines and even across sites of knowledge production, from universities to community colleges to cultural heritage institutions. Scholars and instructors undertaking digital humanities work share an interest in the intersection between computers and cultural artifacts, including novels, films, maps, diaries, devotional manuals, songs, statues, illuminated manuscripts, relics, ancient ruins, and even computers themselves.

Despite popular pronouncements that "technology is taking over" humanities departments (Kirsch 2014) or that "big data is coming for your books" (Marche 2012), much of the work undertaken by digital humanists alters the methodologies but not the fundamental questions of humanistic scholarship. Questions about the authorship of texts, about historical events, about changes in populations over time, about communal and individual identity, and about style and genre dominate digital humanities scholarship, just as they do traditional humanities research and teaching. In the best digital humanities work, the hermeneutic, interpretive, and creative capacities of the scholar or student's mind are supplemented, rather than replaced, by the work of the computer.

Because of their close association with ever-developing technologies, the digital humanities can project an aura of perpetual newness - what Bethany Nowviskie (2012) has called the "eternal September" of the digital humanities. The field has gained particular prominence in the past decade with the founding of the NEH's Office of Digital Humanities in 2008 and increased support from other funding agencies like the Andrew W. Mellon Foundation. The rise of Web 2.0 has lowered barriers to entry in the field, with user-friendly platforms like WordPress and Twitter making it easier for scholars interested in digital projects to communicate with one another, share results, craft projects, and offer basic skills training. Ongoing support from granting agencies has also allowed DH centers and institutes like the Roy Rosenzweig Center for History and New Media (George Mason University), the Institute for Advanced Technology in the Humanities (University of Virginia) and the Center for Digital Research in the Humanities (University of Nebraska-Lincoln) to thrive.

But despite their seeming newness, the digital humanities have a well established history 
marked by the convergence of multiple disciplinary threads. The field of computational linguistics, which uses computers to study language by amassing corpora of linguistic data and analyzing these corpora with the help of computer programs, is one of the oldest and best established (Jensen 2014). Scholars in the disciplines of rhetoric and composition have long been interested in the role that technology plays in the creation and dissemination of text; their research into computers and writing, which dates to at least the 1970s, provides an important intellectual source for current digital humanities work. Scholars in the fields of media and communication studies have also spent decades studying the role of analog and digital media in producing and reflecting culture; much current digital humanities work arises from this disciplinary source. And educators have been measuring the impact of technology in the classroom since personal computers became available in the 1980s; much current scholarship in the digital humanities grows out of and continues to advance the work of digital pedagogy.

Scholars seeking a single moment of origin for the digital humanities often point to Father Roberto Busa's work on the Index Thomisticus, a computerized concordance of the works of St. Thomas Aquinas that Busa began pursuing in collaboration with the IBM Corporation in the 1950s. Busa was engaged in an act of computerized textual analysis-one that basic indexing software can now perform with ease. But he was ahead of his time in considering how computer technology might be applied to humanistic materials, and his role as a Jesuit priest and professor of theology places the early years of the digital humanities squarely in the field of religious studies (Kirschenbaum 2012; Koh 2014). In addition to this explicit genealogy, religious history informs the digital humanities in less obvious ways. Much of the work performed by digital humanists involves the preservation, manipulation, and study of historical records, texts, and images-materials often preserved through the efforts of religious institutions. The past work of religious communities thus makes the present work of digital humanists possible. And yet the field of religious studies has lagged behind other disciplines in embracing the digital humanities (Pasquier 2010). Religion and religious studies are thus both central and oddly peripheral to the current $\mathrm{DH}$ moment. 
This essay serves two primary purposes: to highlight the types of scholarly and pedagogical work that fall under the heading of "digital humanities" — from digital archiving and curation to mapping and visualization to textual analysis and distant reading-and to provide examples of work in these areas that is either produced by or may be of interest to scholars of North American religions. ${ }^{2}$ As an emergent set of methodologies with the potential to alter all aspects of research and pedagogy, developments in the digital humanities should be of concern even to scholars not directly engaged in digital work.

\section{$\underline{\text { Archives, Research Collections, and Databases }}$}

Some of the oldest and best-known digital humanities projects are digital collections: archives, exhibits, and databases with digitized or born-digital collections of materials made available to scholars and the public for study. The earliest digital collections predated the world wide web; digitized materials were preserved on magnetic tape, floppy disk, or CD-ROM. The advent of the web and the launch of the Mozilla web browser ushered in a new era of digital collection and presentation, and as the cost of digitization and storage space has dropped and web technologies have become more advanced, the amount of digital material available online has skyrocketed. Museums and libraries increasingly make their digital collections public and researchers build archives devoted to significant authors, artists, communities, and movements. Even scholars who have never considered themselves digital humanists have almost certainly used many of these collections in their research or teaching.

\section{Scholarly Digital Archives}

The ideal scholarly digital archive offers a cluster of materials that enable detailed study of an author, artist, community, topic, or collection. Scholarly digital archives present highquality electronic editions of texts or images alongside editorial tools that allow for deep and sustained study of the subject at hand. For many observers, the term "online archive" conjures visions of Google Books or Project Gutenberg. But while both are useful sites for 
superficial reading and browsing, neither meets the highest standards for scholarly digital archives:

- High-resolution, color-corrected images of the original physical artifacts

- Reliable transcriptions of text, preferably encoded according to the standards of the Text Encoding Initiative (TEI) ${ }^{3}$

- Accurate and consistent metadata across the collection; depending on the materials represented this metadata might include the date of an artifact's creation, measurements of its size and shape, a description of its material composition (laid paper, tone, bronze, charcoal, 10MB JPG image, etc.), and the name and location of the collection where it is housed

- A thorough explanation of the editorial standards and processes used to create the archive, including standards for digitization of material artifacts

Digital archives and editions, like all scholarly projects, have varying purposes, audiences, and levels of quality. Not all of the projects mentioned here meet all of the standards for high-quality digital archives listed above, but they may nevertheless be of use and interest to scholars of North American religions.

Many digital archives feature items from a particular institution or collection. The Documenting the American South project, launched at the University of North Carolina at Chapel Hill in 1996, includes digital editions of manuscript and print materials in UNC collections. Editions are encoded according to the TEI guidelines and include highresolution page images, accurate transcriptions, and scholarly introductions and notes. Of the thousands of documents made available, scholars of North American religions may find the Church in the Southern Black Community, North American Slave Narratives, and First Person Narratives of the American South collections particularly useful. The Occom Circle, hosted at Dartmouth College, includes digital editions of over 500 documents by the Mohegan minister Samson Occom and his correspondents, encoded according to the TEI Guidelines and annotated and cross-referenced. While the site contains only materials held at Dartmouth, links are provided to other important collections of Mohegan materials. Other institutions that make digital collections available to scholars include the 
Congregational Library and Archives, the Massachusetts Historical Society, the American Antiquarian Society, and the Church of Jesus Christ of Latter-Day Saints.

Other archives cross collections and feature information and online editions devoted to a particular genre, person, or event. The Transcribing Early American Sermons (TEAMS) project, led by Zachary Hutchins of Colorado State University, is a recently launched collection of carefully transcribed manuscript sermons from the early years of colonial settlement. At this writing the project's database contains only 26 sermons, but includes materials by Native American and African-American preachers in addition to EuropeanAmerican clergy and by Catholics and Episcopalians as well as Congregationalists and Presbyterians. The online presence of the \onathan Edwards Center at Yale University offers an extensive collection of digital editions of Edwards's writings as well as useful resources about his biography and theology. While the Center's editions do not employ the TEI they are painstakingly edited and include many works never or no longer available in print as well as a bibliography of other editions. Both TEAMS and the Edwards Center invite participation by volunteers who wish to assist with transcription. The Joseph Smith Papers, an online edition supplemented by print volumes, is, like the Edwards editions, exhaustive, rigorous, and editorially transparent. The Isaac Mayer Wise Digital Archive, hosted by Hebrew Union College, provides over 20,000 digital images and transcribed texts of public and private documents written by the father of American Reform Judaism. Scholars of religion and literature may be particularly interested in the Walt Whitman Archive, the Melville Electronic Library and the Emily Dickinson Archive. And the Papers of Abraham Lincoln project aims to eventually publish digital images and TEI-encoded transcriptions of every document written by or to Lincoln during his lifetime. ${ }^{4}$

As noted above, the digital humanities, far from being a new phenomenon, have existed for decades. This means that useful projects survive on the world wide web but are no longer publishing new materials. Two that remain pertinent to scholars of American religions are the Salem Witch Trials Documentary Archive, which contains electronic editions and maps related to the 1692 witchcraft accusations, and the Valley of the Shadow, an interactive site that presents Civil War documents from Augusta County, Virginia, and Franklin County, 
Pennsylvania. While neither site is currently being updated, both remain excellent sources of information as well as interesting examples of early work in humanities computing.

Research Collections and Databases

Whereas digital archives usually present painstakingly edited digital editions of images or texts intended for careful study, research collections and databases often have a broader purpose and a wider public audience, combining digital images, exhibit text, and even teaching materials in an easily accessible online format. Unlike digital scholarly archives, textual materials are often presented without transcription, and metadata standards for included materials can be inconsistent. Nevertheless, these digital collections often prove invaluable for teaching and research.

As with digital archives, online research collections often showcase materials in a particular institution or repository. Inuvialuit Pitqusiit Inuuniarutait: Inuvialuit Living History is a collaborative site dedicated to the exploration and sharing of Inuvialuit materials in the MacFarlane Collection at the Smithsonian Museum. The Living History project brings native community members together with Smithsonian staff to create a "living collection" for use by Inuvualit people and interested members of the public. Out of Many: Religious Pluralism in America is a collection of items at the Newberry Library related to religious diversity in different geographic settings. The product of an NEHfunded institute, the site contains images and essays on topics ranging from the religious history of Atlanta, Georgia, to Islam in the American Midwest. Curators at the Magnes Collection of Jewish Art and Life at the University of California at Berkeley have created extensive digital exhibits, timelines, and image and video collections that make their holdings available to online visitors. Reed College's online Indian Converts Collection features images, documents, maps, and teaching guides related to communities of "Christianized Indians" in New England. The Pittsburgh Jewish Newspaper Project provides access to scanned Jewish newspapers from the Posner Memorial Collection at CarnegieMellon University. The Jewish Joint Distribution Committee makes its text and video archives available for searching and viewing online. And the USC Shoah Foundation's Visual 
History Archive Online collects video interviews with Holocaust survivors and witnesses to other genocidal events; while some videos can be viewed online, others are available onsite at research institutions around the world.

Other research collections feature thematic materials or those collected by a team of scholars. The Center for the Study of Material \& Visual Cultures of Religion's MAVCOR site presents digital images and publishes peer-reviewed scholarship related to visual cultures of religion around the world. Materials on the site can be filtered according to geographic location, religious tradition, and other criteria to allow for targeted research. The 」ewish Atlantic World Project, hosted by the Reed College Libraries, includes photographs of North American and Caribbean Jewish artifacts collected by Dr. Laura Leibman; the searchable and browsable site includes examples of architecture, funerary art, household items, and documents from individuals and communities as well as teaching and reference materials. In Motion: The African American Migration Experience, a project of the Schomburg Center for Research in Black Culture at the New York Public Library, offers an exhaustive collection of texts, illustrations, and maps grouped thematically around thirteen major African-American migrations. Religious themes include indigenous African religiosity, the influence of Haitian Vodou on North American religious life, and the rise of AfricanAmerican Protestant denominations.

The Lesbian, Gay, Bisexual and Transgender Religious Archives Network (LGBT-RAN) serves a number of purposes both scholarly and devotional. Hosted by the Center for Lesbian \& Gay Studies in Religion and Ministry, LGBT-RAN sponsors and hosts online exhibits related to LGBT history and spirituality, collects oral histories from LGBT religious leaders and allies, and gives an annual award for outstanding scholarship in LGBT religious history. A research collection of a different sort can be found at the site of the Frequencies project, a "collaborative genealogy of spirituality" consisting of one hundred essays on ideas, objects, and phenomena defined by the contributors as "spiritual." Rather than digitizing and curating existing materials, the site's contributors offer meditations, deconstructions, or artistic reflections on topics ranging from the double helix to the ChickFil-A sandwich. 
Many sites, rather than digitizing and hosting materials themselves, serve as online clearinghouses that can point scholars and adherents to materials of interest that may be scattered across sites or institutions. The Religion in Kansas Project aggregates catalog and holdings information from religious communities and cultural institutions around the state, emphasizing the religious diversity of the Midwest. The Locating Lutheranism project hosted by St. Olaf College is in the early stages of collecting and curating materials related to Norwegian-American Lutheran congregations in Minnesota. Jews in America: Portal to Lewish American History aggregates collection information from over 350 institutions with materials related to the history and practices of Jews in America. And the Religion in North Carolina Digital Collection, hosted by Duke University's Divinity School, features materials from archives across North Carolina and provides a useful, state-specific supplement to the Documenting the American South digital archive.

Some sites act primarily as online bibliographies or finding aids. The American Converts Database, led by Erin Bartram and Lincoln Mullen, is a growing list of religious converts and conversions in American history. The collection draws on sources ranging from WPA slave narratives to the Library of Congress's Chronicling America newspaper database; visitors are encouraged to add entries through a submission form. Southern Manuscript Sermons Before 1800 is a browsable and searchable bibliography of over 1600 known manuscript sermons from colonial and early national Maryland, Virginia, North Carolina, South Carolina, and Georgia. The Gateway to Early Modern Manuscript Sermons (GEMMS) aims to provide a similarly comprehensive finding aid for manuscript sermons held in repositories across the United Kingdom, Ireland, the US, and Canada.

As a well-established branch of the digital humanities, digital archiving, collecting, and curation have been successfully adapted to pedagogical purposes. Collaborations between instructors, librarians, and students can produce fine web-based projects that showcase a particular collection or community while providing a public outlet for student writing and research. Brick and Mortar: Pieces of Catholic Chicago, created by Christopher Cantwell and students at the University of Illinois-Chicago, includes student essays on important artifacts 
in UIC's special collections. The \esuit Libraries Project and \esuit Libraries Provenance Project are research and pedagogy endeavors devoted to studying the original 1878 library catalog of St. Ignatius College (now Loyola University Chicago) and tracing the provenance of materials at Loyola and in North American Jesuit libraries.

\section{Digital Mapping and Data Visualization}

Like digital archiving and collecting, computer-assisted mapping and visualization projects have been undertaken by scholars for decades. Geographers and historians, in particular, have used Geographic Information Systems technologies to both supplement traditional scholarship and investigate new questions. But GIS applications can be expensive to access and difficult to learn, and the recent rise of user-friendly web-based and mobile interfaces (most famously Google Maps) for accessing and working with spatial data has made digital mapping and other forms of visualization more accessible for purposes of both research and pedagogy.

As Lincoln Mullen has noted, "there is an enormous amount of (potentially) spatial data about religion that historians have long known about but haven't known what to do with" (2015). One early project that sought to make use of spatial data for the purpose of visualization was French and Spanish Missions in North America; the project used a nowdefunct map creation tool called TimeMap to plot colonial era mission activity, and while the site survives, the dynamic maps are no longer accessible. A more recent project is Houses of Worship, which combines features of a digital research collection and an online mapping project to present and plot information about congregations that developed in Minneapolis-St. Paul between 1849 and 1924. The Religious Soundmap Project of the Global Midwest, headed by scholars Amy DeRogatis and Isaac Weiner, will combine field recordings of religious soundscapes with mapping technologies to produce a soundmap of religious practice in Midwestern communities. The project will be collaboratively produced by students, faculty, and the public, and while it is still in its early stages, Weiner's students at Ohio State University are already Listening for Religion in central Ohio. Materializing the 
Bible, a project by scholars and students at Miami University in Ohio, offers a digital map, online catalog, and study materials related to Bible-based attractions around the world. One recent and interesting project uses simple online mapping technology to trace, not religious history or adherence per se, but trends in the study of those phenomena. The Bibliography of Urban American Religious History includes citations for 170 scholarly works on religious history along with a map indicating the most-studied cities.

Scholars seeking information about religious activity and adherence in certain geographic regions or among particular populations would do well to consult place-based or thematic mapping projects, which often enfold detailed information about a city or state's religious character even when not devoted explicitly to such subjects. Examples of such projects include Digital Harlem, which features a section devoted to black religious practice in the early twentieth century; and PhilaPlace, a digital map and documentary archive that explores Philadelphia (including its religious life) through the lens of its diverse neighborhoods. Scholars at a number of institutions have also used digital mapping technologies and the study of historical documents to lay bare the attempted destruction of African-American religious and civil life during the twentieth century: see Redlining Richmond and Mapping Decline: St. Louis and the American City for examples.

Some of the most interesting religious studies work in spatial digital humanities and visualization has been conducted at Indiana University-Purdue University Indianapolis's Polis Center, which supports the Digital Atlas of American Religion (DAAR) and the Project on Religion \& Urban Culture. The DAAR aggregates data about U.S. religious adherence from 1890 to the present and offers users tools for visualizing this information. Because the data sources that support the DAAR are varied and adhere to differing standards, and because mapping and visualization processes run the risk of oversimplifying complex information, the creators of the DAAR have made the origins and parameters of their source data very explicit. But the project is necessarily bound by the limitations of survey and census methods for capturing religious adherence and experience: Christian and Jewish adherence are easiest to record and to visualize, while minority religions and religious activities not defined by membership in a registered religious community escape attention. ${ }^{5}$ 
Mapping Ararat, led by Melissa Shiff, Louis Kaplan, and John Craig Freeman, challenges the concretization of religious experience by mapping imaginary geographies of uncreated space. The project team pushes the theoretical boundaries of digital cartography by creating virtual representations and counterfactual histories of Mordecai Noah's failed Ararat community in Grand Island, New York. Visitors to the project site or to Grand Island can take a Virtual Reality Walking Tour of the town that never was, complete with imagined public buildings, local currency, and movie posters.

A number of sites combine the features of an archive, a research collection, and a digital map to explore a topic across time and space while also providing scholarly commentary and access to archival materials. Mapping Jewish LA uses a combination of Scalar (see below) and the HyperCities digital mapping platform to create curated exhibits that contextualize archival materials within the geographic and historical matrix of Los Angeles. Building Islam in Detroit: Foundations, Forms, Futures combines virtual exhibits and oral histories with a map and information about local mosques to explore the vitality of Islamic life in that city.

Digital mapping is a widely recognized form of data visualization, but digital humanists create other kinds of visualizations as well. Jessop (2008) distinguishes between visualization and illustration by noting that a "visualization departs from being an illustration when it becomes the principal medium of communication," i.e. when the visualization transmits information rather than merely accompanying or elucidating a textual transmission. One popular form of visualization among digital humanists is network analysis, which applies the network theories and techniques developed by data scientists to humanistic materials. The goal of network analysis is to tease out and visualize the interconnected relationships between persons, locations, or events in a single narrative or a collection of texts. Large-scale network analysis can reveal unexpected connections between people of different social classes or political persuasions or uncover trade routes between regions or countries that have not been preserved in historical records. Lauren Klein (2013) of Georgia Tech has used a combination of network analysis and very close 
reading to uncover details about the lives of Thomas Jefferson's enslaved laborers, who receive only passing mention in his papers. By identifying and connecting mentions of "Jimmy" or "Jaime" in Jefferson's letters, Klein has discovered new details about the life of James Hemings, Jefferson's cook and Sally Hemings' older brother, and demonstrated how digital textual analysis can deepen our engagement with the archive.

\section{Computerized Textual Analysis and "Distant Reading”}

The branch of the digital humanities that has received the most attention in the recent popular press is that group of methodologies known as "distant reading." "Distant reading" is a term coined by literary scholar Franco Moretti to describe methods by which scholars aggregate humanistic materials-usually but not exclusively texts-and then "read" those materials with the aid of computer programs. Distant reading methods raise suspicion among both scholars and the public because they seem to fly in the face of much traditional humanistic work, bypassing the processes of canon formation and historical narrativizing that not only structure humanistic disciplines but also form much of our shared cultural identity. But in many cases distant reading simply offers new ways of answering traditional humanities questions and supplements rather than replacing traditional techniques of archival recovery, textual editing, historical contextualization, and close reading. Moretti's Graphs, Maps, Trees and the freely available pamphlets published by the Stanford Literary Lab offer multiple examples of how distant reading methodologies can enhance traditional modes of scholarship.

Two of the most well known distant reading methodologies are text mining and topic modeling. In text mining, scholars collect large amounts of textual data-all of the nineteenth-century novels available in the HathiTrust Library, for instance-and use programming commands to determine the frequency of particular words or phrases, track the appearance of new vocabulary, compare word choice and stylistic characteristics among groups of authors, and perform other computationally viable tasks. In topic modeling, an algorithm combs through a large dataset and returns a list of frequently occurring topics based on the co-location of common words. ${ }^{6}$ 
Just as we have seen with other digital humanities methodologies, while the term "distant reading" may be new, the use of computer programs to classify and study texts reaches back several decades. Scholars began pursuing computer-assisted stylometric analyses of the Book of Mormon and other early LDS texts, for instance, in the late 1970s, but recent advances in the field of linguistic computing have spurred increased efforts. Scholars at Stanford University have used the stylometric techniques of delta and shrunken centroid classification to test various theories for the Book of Mormon's authorship (Jockers et al 2008; Jockers 2013), while researchers at New York University have used the pseudonymously authored 1855 anti-Mormon novel Female Life Among the Mormons to develop a methodology for author attribution using a very small number of texts (Hoover \& Hess 2009).

Distant reading methodologies can be combined with other types of scholarship to both raise new questions and answer old ones. The University of Richmond's Hidden Patterns of the Civil War applies multiple methods of digital analysis to its very broad topic. The project features electronic editions of the Richmond Daily Dispatch and the papers of the Virginia Secession Convention; maps and visualizations of Richmond's slave market, Civil War-era election patterns, and the progress of Emancipation across the South; computational analyses of historical newspapers; and topic modeling experiments using the text of the Dispatch.

\section{Getting Started in the Digital Humanities}

Many scholars not already immersed in the discourse of the digital humanities are reluctant to enter the field, whether because recent attention to digital work makes it seem faddish or because they doubt whether the use of digital tools adds anything substantive to the study and teaching of the humanities. Others are curious about the potential of digital methodologies but legitimately concerned about the ways in which the transformation of humanistic knowledge into quantifiable data might distort or dehumanize our subjects of 
study. However, for those who wish to learn more about the field and perhaps to pursue digital projects themselves, many resources are available.

Scholars who identify with the term "digital humanist" generally value open dialogue in forums that are faster and more accessible to immediate critique than traditional scholarly journals. Many DH scholars track the progress of their research and pedagogy on professional blogs or in open-access, collaboratively edited journals like Hybrid Pedagogy and the Lournal of Digital Humanities. This means that after a few hours of following hyperlinks from a scholar's blog to Digital Humanities Now to Digital Humanities Quarterly, interested scholars can already begin to see the contours and controversies of the field taking shape. ${ }^{7}$ For those wishing to acquire new skills, in-person workshops like the Digital Humanities Summer Institute and the Humanities Intensive Learning and Teaching Institute, online training courses, and tutorials are widely available; resources for learning TEI encoding and publishing are particularly plentiful.

For scholars considering a new digital archive, research collection, or exhibit, a number of platforms are available. While some scholars rely on popular blogging software like WordPress, teams of developers invested in the scholarly future of the digital humanities have developed their own tools. Omeka, a platform supported by the Rosenzweig Center for History and New Media, helps scholars and students create digital exhibits while adhering to high standards for metadata curation. The Colored Conventions Project at the University of Delaware is built with Omeka and uses the platform's Scripto plugin to crowdsource transcriptions of nineteenth-century materials. The Mukurtu content management system is being developed in collaboration with indigenous communities to facilitate the responsible sharing of cultural heritage materials. And media studies scholars at the Alliance for Networking Visual Culture at the University of Southern California have developed Scalar, a platform for producing media-rich digital content for scholarly and pedagogical use. The Claremont Center for Digital Humanities' “Performing Archive: Edward S. Curtis and 'the Vanishing Race'" provides an example of critical media studies work using Scalar. 
Increasing interest in computerized textual analysis has inspired a number of out-of-thebox programs for performing basic computational analyses of text. Google's $\mathrm{N}$-gram viewer, which graphs the frequency of terms across the entire Google Books database, is perhaps the most famous, but given Google's haphazard digitization policies and uncorrected text, its results should always be taken with skepticism. See Altman (2012) for an example of the kind of basic analysis that the N-gram viewer facilitates. Voyant Tools is a web application created by Stéfan Sinclair and Geoffrey Rockwell that can create word clouds, frequency graphs, and other visualizations from plain-text or encoded XML data. Paper Machines is a plug-in for the Zotero bibliographic management system (itself a creation of the Rosenzweig Center) that can perform similar operations on Zotero collections. Gephi provides basic network visualization tools and Mallet is an out-of-the-box software package for topic modeling purposes. Each of these packages has the advantage of being relatively easy to install and learn, but the less one knows about the principles behind the software, the more likely one is to misinterpret the results. For an example of how the basic features of Voyant, Mallet, and Paper Machines can be used responsibly to explore a small corpus of thematically related documents, see Lincoln Logarithms, a seminar project produced by graduate students at Emory University that uses a collection of sermons on the assassination of Abraham Lincoln to test the affordances of these three tools. For a more extensive list of digital tools for teaching and research, see DiRT (Digital Research Tools Directory), a clearinghouse and review site for digital humanities applications.

\section{Conclusion}

As a cluster of research and teaching methodologies that explore the intersection of modern technologies and human cultural production, the digital humanities are likely to continue holding a central place in scholarship and pedagogy. The projects and sites collected here offer examples of the many directions that digital humanities scholarship in North American religions might take. But further work needs to be done. Scholars of religion must interrogate how the quantification and regularization required by digital projects distorts the description and representation of religious experience. They must 
consider how the distribution of digital humanities funding by cultural heritage institutions and granting agencies privileges some religious traditions over others. And they must weigh new models of digital pedagogy that affect the teaching of religious belief, history, and practice. Scholars of religion have been reluctant to adopt the methodologies of the digital humanities, but their insights are needed. 


\section{References}

Altman, M. (2012) Asian religions in America as an ngram: Hinduism, Buddhism, and the Rammohun spike. Religion in American History 22 March [Online]. Retrieved 12 January 2016 from http://usreligion.blogspot.com/2012/03/by-michael-j.html

Burdick, A. (2012). Digital_Humanities, Cambridge, MA: MIT Press.

Cantwell, C. (2015). The digital futures of religious studies. Religious Studies News 2 March [Online]. Retrieved 7 January 2016 from http://rsn.aarweb.org/articles/digital$\underline{\text { futures-religious-studies }}$

Cantwell, C.D. \& Rashid, H. (2015). Religion, media, and the digital turn. Social Science Research Council: NY. Retrieved on 2 January 2016 from http://www.ssrc.org/publications/view/religion-media-and-the-digital-turn/

Drucker, J. (ed.) (2013). Intro to Digital Humanities. Los Angeles: UCLA Center for Digital Humanities. Retrieved on 11 November 2015 from http://dh101.humanities.ucla.edu/

Dunn, S., Kadish, L., \& Pasquier, M. (2013). A religious center with a civic circumference: Towards the concept of a deep map of American religion." International Journal of Arts and Humanities Computing 7(1-2), pp. 190-200. [Online]. Retrieved on 24 November 2015 from EBSCOhost database.

Gold, M.K., \& Klein, L. (eds.). (2012). Debates in the Digital Humanities. Ann Arbor: University of Minnesota Press. http://dhdebates.gc.cuny.edu/

Hirsch, B. (ed.) (2013). Digital Humanities Pedagogy: Practices, Principles and Politics. Open Book Publishers.

Hoover, D.L. \& Hess, S. (2009). An exercise in non-ideal authorship attribution: the mysterious Maria Ward. Literary and Linguistic Computing 24(4), pp. 467-489.

Hutchings, T. (2015). Digital humanities and the study of religion. In: Svensson, P. \& Goldberg, D.T. (eds.), Between Humanities and the Digital. Cambridge, MA: MIT Press.

Jensen, K.E. (2014). Linguistics in the digital humanities: (Computational) corpus linguistics. MedieKultur: Journal of Media and Communication Research 30(57). [Online]. Retrieved on 3 February 2016 from EBSCOhost database. Jessop, M. (2008). Digital visualization as a scholarly activity. Literary and Linguistic 
Computing 23(3), pp. 281-93.

Jockers, M.L. (2013). Testing authorship in the personal writings of Joseph Smith using NSC classification. Literary and Linguistic Computing 28(3), pp. 371-381.

Jockers, M.L., Witten, D.M. \& Criddle, C.S. (2008) Reassessing authorship of the Book of Mormon using delta and nearest shrunken centroid classification, Literary and Linguistic Computing, 23(4), pp. 465-91.

Kirsch, A. (2014). Technology is taking over English departments. New Republic 20 May [Online]. Retrieved on 20 May 2014 from https://newrepublic.com/article/117428/limits-digital-humanities-adam-kirsch

Kirschenbaum, M. (2012). What is digital humanities and what's it doing in English departments? In: Gold \& Klein (eds.), Digital Humanities. Minneapolis: University of Minnesota Press. http://dhdebates.gc.cuny.edu/

Klein, L.F. (2013). The image of absence: archival silence, data visualization, and James Hemings. American Literature, 85(4), pp. 661-688. [Online]. Retrieved on 15 November 2015 from Duke Journals Online http://americanliterature.dukejournals.org

Koh, A. (2014). Niceness, building, and opening the genealogy of the digital humanities: Beyond the social contract of humanities computing. Differences: A Journal of Feminist Cultural Studies 25(1), pp. 93-106.

Marche, S. (2012). Literature is not data: Against digital humanities. Los Angeles Review of Books 28 October [Online]. Retrieved on 28 October 2012 from https://lareviewofbooks.org/essay/literature-is-not-data-against-digitalhumanities

Mullen, L. (2015). What the map of urban religious histories shows us. Religion in American History 20 October [Online]. Retrieved on 22 January 2016 from http://usreligion.blogspot.com/2015/10/what-map-of-urban-religioushistories.html

Nowviskie, B. (2012). Eternal September of the digital humanities. In: Gold \& Klein (eds.), Debates in the Digital Humanities. Minneapolis: University of Minnesota Press. http://dhdebates.gc.cuny.edu/ 
Pasquier, M. (2010). American religion and digital humanities. Religion in American History

9 March [Online]. Retrieved on 28 January 2016 from:

http://usreligion.blogspot.com/2010/03/american-religion-and-digital.html

Svensson, P. \& Goldberg, D.T. (eds.) (2015). Between Humanities and the Digital. Cambridge, MA: MIT Press.

Terras, M.M., Nyhan, J., \& Vanhoutte, E. (eds.) (2013). Defining Digital Humanities: A Reader. Burlington, VT: Ashgate Publishing Limited.

1 The reasons are as much institutional as philosophical. The American Academy of Religion, "[u]nlike other major scholarly associations,... has yet to arrive at a set of standards that evaluates digital scholarship by taking into account its unique characteristics" (Cantwell 2015).

${ }^{2}$ In order to keep the topic manageable, this essay discusses digital projects related to North American religions and created by scholars or public heritage professionals for the use of researchers, religious communities, or the general public. It excludes for-profit, subscription-only database products as well as scholarly journals. For a broader view of the relationship between religious behavior, religious studies, and digital technologies, see the Social Science Research Council's report on Religion, Media, and the Digital Turn (2015). Hutchings (2015) also provides a useful primer on digital humanities and the study of religion.

3 The TEI is an organization of scholars, librarians, and computer scientists committed to developing an open-source standard for encoding manuscripts and published works in every genre. Encoding - or "marking up"-a text renders its formal elements explicit in a language that is internally consistent and human- and machine-readable. Any information about a text, including its materiality, its design, information about its creator(s) and its provenance, its composition and revision history, can be formalized and standardized through the application of textual markup. 4 The Lincoln Papers Project also publishes The Law Practice of Abraham Lincoln, a searchable online database of legal cases handled by the future president. The Lincoln Log offers a daily chronology of Lincoln's life, with periodic updates by the staff of the Lincoln Papers project. And Lincoln/Net, based at Northern Illinois University, offers a collection of digitized materials, maps, exhibits, and essays for research and pedagogy purposes.

5 To address this problem, the Center hosted an NEH Summer Institute on Deep Maps and Spatial Narratives in 2012. Three of the participants, Stuart Dunn, Lesley Kadish, and Michael Pasquier, published their preliminary findings in 2013.

One effort to access less concrete, geographically located, or textually based expressions of religiosity can be found in the SoulPulse project. The SoulPulse research team sends smartphoneenabled surveys to participants twice a day with a series of questions related to spirituality. The team of psychologists and sociologists reports preliminary findings on their blog and rewards subjects with a personalized report after fourteen days of participation.

${ }^{6}$ For an example of large-scale text mining and topic modeling techniques applied in a humanities field, see The Indiana Philosophy Ontology Project (InPho).

7 Scholars who prefer more traditional forms may wish to consult Burdick 2012, Drucker 2013, Gold \& Klein 2012, Hirsch 2013, and Svensson \& Goldberg 2015. 